\title{
Parenting and Psychopathology in Sibling Pairs
}

\author{
Jiri Modestin \\ Karin Marrer \\ Puspa Agarwalla
}

University of Zurich, Department of Psychiatry

Burghölzli Hospital, Zürich

SWITZERLAND

\begin{abstract}
Background: The current study explored the relationship between parenting experience in childhood as a specific aspect of the non-shared environment and the amount of psychopathology in adulthood.

Sampling and Methods: 27 same-sex sibling pairs were studied. In each pair, one proband was a psychiatric outpatient, the other proband a non-patient. All probands filled in the Parental Bonding Instrument (PBI) and the Symptom Checklist-90-Revised (SCL-90-R).

Results: The patients rated higher on practically all SCL-90-R scales whereas no significant differences were found with regard to the PBI ratings. With only one exception, there were no significant correlations between PBI and SCL-90-R ratings in the group of patients. In contrast, all SCL-90-R subscales correlated negatively with paternal care and half of them positively with paternal control in patients' healthy siblings.

Conclusions: The degree of paternal care seems to be most closely related with lack of mental symptoms in psychiatric non-patients. In contrast, parenting does not seem to play a substantial role in patients, presenting with a higher degree of psychopathology. Obviously, environmental factors become less important, the more pronounced the pathology.
\end{abstract}

Received 26 July 2007

Revised 7 May 2008

Accepted 16 June 2008

\section{Introduction}

Currently, as in the past, there is an interest in the study of possible environmental antecedents of psychopathology and behavioral deviance. Regarding differences in personality - briefly defined as a totality of behavior and inner experience - and in psy- chopathology, shared environment seems to play only a marginal role ${ }^{1}$, even though it may have more effect in extreme situations. Differential treatment of children by their parents in the same family or differential perceptions of such treatment by children represent a systematic non-shared environmental influence. Apart of genetic influence, the variance component of such a non-shared environment is 
the source of differential outcomes ${ }^{2,3}$. Parental bonding can be viewed as a specific aspect of the non-shared environment ${ }^{4,5}$. Correspondingly, parenting experiences, particularly lack of care, have been found to be potentially causally related in a non-specific manner to a wide range of adult psychopathology $\mathrm{y}^{6}$, including depression ${ }^{7-9}$, personality disorders ${ }^{10,11}$ and substance abuse ${ }^{12,13}$.

We explored whether there is a connection between early environmental influences in terms of parenting experience (parental bonding) in childhood and the amount of psychopathology in adulthood. In order to control for at least some of the many other potential influences, the study was carried out on same-sex sibling pairs; to increase the psychopathology variance, one of the siblings was a psychiatric patient, the other one a psychiatric non-patient. Our hypothesis was 1. that patients would score higher on psychopathology measures (confirming the difference in outcome), 2. that they would indicate suboptimal parental bonding more frequently (score lower on parental care, higher on parental control), and 3. that the psychopathology and parental bonding ratings would correlate with each other. We were particularly interested in a possible differential effect parenting could exert on psychopathology in both subgroups, patients and their healthy siblings; this topic has seldom been addressed in the literature.

\section{Methods}

\section{Procedure}

The study design was approved by the local ethical committee. The patients were recruited at the Psychiatric Outpatient Service Zürich-Oerlikon, and the patients stated the identity of their siblings. The pairs were included in the study provided they gave their written informed consent, spoke German fluently, and were prepared to deliver basic socio-demographic data and to fill in the study questionnaires. In the case of the patients having more than one samesex sibling, the one with the smallest age difference to the patient was included.

\section{Probands}

Altogether, 27 proband pairs (54 probands) were studied. In each pair, one proband was a psychiatric outpatient, the other proband his or her sibling of the same sex. According to a self-declaration, the latter had never had the status of a psychiatric inpatient and/or outpatient. There were 10 male and 17 female pairs; the group of patients and siblings did not differ with regard to age $(\mathrm{MN}=38$ years, $\mathrm{SD}=13$ in both groups; $\mathrm{Z}=0.40, p=0.69$ ) even though there were more pairs with an older patient than an older sibling (70\% vs $30 \% ; \chi^{2}=8.96$, df $\left.=1, p=0.003\right)$. More healthy siblings were married (44\% vs $22 \%$ ) and less were divorced/separated (15\% vs $30 \%$ ), but the difference in the marital status was not statistically significant $\left(\chi^{2}=3.50\right.$, df $=2, p=0.17)$. More patients belonged to the lower social class $\left(39 \%\right.$ vs $16 \% ; \chi^{2}=3.24$, df $=1, p=0.072$ ). The patients were diagnosed according to the ICD-10 14 classification: 10 (37\%) received the principle diagnosis F2 (schizophrenia spectrum disorder); 9 (33\%) received the diagnosis $\mathrm{F} 3$ (affective disorder); and $8(30 \%)$ received the diagnosis $\mathrm{F} 4-7$ (most of them neurotic disorder).

\section{Instruments}

\section{Parental Bonding Instrument (PBI)}

The $\mathrm{PBI}^{15}$ measures various attitudes and behaviour of parents as they are remembered 
retrospectively by an individual having occurred in his or her first 16 years. The attitudes of each parent are evaluated separately, and the scale consists of 25 items reflecting two dimensions: the dimension of care/involvement vs. indifference/rejection (12 items) and the dimension of control/overprotection vs. encouragement of autonomy/independence (13 items). All items are rated on a Likert scale ranging from 0 to 3. The original 3-week test-retest reliability assessment yielded a Pearson correlation coefficient of 0.76 for the care scale and 0.63 for the control scale ${ }^{15}$. Satisfactory reliability and validity of PBI have been confirmed in numerous subsequent studies ${ }^{16}$ and its longterm stability over time has been demonstrat$\mathrm{ed}^{17}$. The instrument was developed, amongst other reasons, for examining the influence of possible distortions of parental bonding on the psychological functioning of the recipients. The instrument measures the recipient's later judgment of the parents; nevertheless, the lack of an association between the recipient's age and scores on the scale suggest that there is no change in the report of parental attitudes over time. Incidentally, the two dimensions do not appear to be independent; control is linked with lack of care ${ }^{15}$.

\section{Symptom Checklist-90-Revised (SCL-90-R)}

SCL-90-R ${ }^{18}$ is a measure of self-reported psychopathology for use in psychiatric and medical settings. It enables to assess a broad range of psychological and physical symptoms and their intensity at a specific point in time. The scale contains 90 items which are evaluated using a Likert scaling from 0 to 4 . The test helps measure 9 primary symptom dimensions (somatization, obsessions-compulsions, interpersonal sensitivity, depression, anxiety, hostility, phobic anxiety, paranoid ideation, psychoticism ). In adition, several global indices such as the Global Severity Index (GSI) can be determined, the latter designed to measure the overall psy- chological distress. The scales have very good psychometric properties. Cronbach's alpha were 0.73-0.90 and test-retest correlation coefficients across a 10 -week period 0.68-0.84 for the individual scales ${ }^{19}$.

\section{Statistical evaluation}

Evaluating the results, $\chi^{2}$ test was used in the case of categorical, and Wilcoxon test for two dependent samples in the case of continuous variables. Further, Spearman rho correlation coefficients were calculated.

\section{Results}

First, the instruments we used were tested for their reliability. Cronbach's alpha values were calculated separately for the patients and their siblings. Regarding PBI, in the patient group, they were 0.92 for the care and 0.94 for the control scale regarding the father, and 0.92 for both scales regarding the mother. In the sibling group, Cronbach's alpha values were 0.93 for the care and 0.91 for the control scale regarding the father, and 0.88 for the care and 0.86 for the control scale regarding the mother ratings. Regarding SCL-90-R, in the patient group Cronbach's alpha values were between 0.83 and 0.94 for the individual symptom scales (except for paranoid ideation scale with a alpha of 0.66); in the sibling group, Cronbach's alpha values were between 0.84 and 0.94 for all individual symptom scales. Cronbach's alpha values were 0.98 and 0.99 for the GSI composite scale in the patient and sibling group, respectively.

As expected, the patients rated higher on all SCL-90-R scales and the differences were statistically significant for the majority of scales (Table I). Regarding PBI scores, the differences between patients and sib- 
lings did not reach the level of statistical significance, even though the patients tended to rate lower on the care and higher on the control/overprotection PBI scales (Table I). Optimal bonding is characterized by high care and low control ratings. A total of 23 patients and 25 siblings rated both parents; an optimal bonding with regard to at least one parent was indicated by $23(92 \%)$ healthy siblings, but only by $15(65 \%)$ patients $\left(\chi^{2}=5.21\right.$, df $\left.=1, p=0.022\right)$.
In Table II, significant correlations between PBI and SCL-90-R ratings are presented, separately for the group of patients and their siblings. As can be seen, with the only exception of paranoid ideation - being positively correlated with high mother control -, there were no other significant correlations in the group of patients. In contrast, all SCL-90-R subscales correlated negatively with paternal care and half of them positively with paternal control.

Table I

Comparison of patients and siblings with regard to SCL-90-R and PBI

\begin{tabular}{lcccc} 
& Patients & Siblings & \multicolumn{2}{c}{ Significance } \\
& $27(100)$ & $27(100)$ & $\mathrm{Z}$ & \\
\hline SCL-90-R scores: MN \pm SD & & & 2.48 & .013 \\
$\quad$ Somatization & $1.01 \pm 0.86$ & $0.53 \pm 0.60$ & 2.45 & .014 \\
Obsessions-compulsions & $1.31 \pm 1.09$ & $0.71 \pm 0.73$ & 1.88 & .060 \\
Interpersonal sensitivity & $1.20 \pm 0.93$ & $0.76 \pm 0.85$ & 2.73 & .006 \\
Depression & $1.42 \pm 1.05$ & $0.71 \pm 0.75$ & 3.04 & .002 \\
Anxiety & $1.07 \pm 0.89$ & $0.53 \pm 0.77$ & 1.26 & .208 \\
Hostility & $0.76 \pm 0.75$ & $0.51 \pm 0.59$ & 2.26 & .023 \\
Phobic anxiety & $0.85 \pm 0.92$ & $0.34 \pm 0.63$ & 2.46 & .014 \\
Paranoid ideation & $0.93 \pm 0.62$ & $0.62 \pm 0.87$ & 2.35 & .019 \\
Psychoticism & $0.72 \pm 0.68$ & $0.45 \pm 0.70$ & 3.15 & .002 \\
Global severity index & $1.07 \pm 0.71$ & $0.58 \pm 0.67$ & 3.73 & $<.001$ \\
Positive symptom distress index & $1.8 \pm 0.6$ & $1.4 \pm 0.5$ & 2.64 & .008 \\
Positive symptom total & $48.1 \pm 22.5$ & $30.8 \pm 23.9$ & & \\
PBI scores: MN \pm SD & & & 1.03 & .30 \\
Mother care & $23.8 \pm 8.7$ & $26.1 \pm 7.3$ & 0.91 & .36 \\
$\quad$ control & $15.0 \pm 9.9$ & $12.0 \pm 7.7$ & 1.22 & .22 \\
Father care & $19.6 \pm 10.0$ & $22.8 \pm 8.9$ & 1.70 & .09 \\
$\quad$ control & $13.3 \pm 10.8$ & $8.9 \pm 8.4$ & & \\
\hline
\end{tabular}

Table II

Correlations between PBI und SCL-90-R rating scales, separately for patients and their siblings

\begin{tabular}{|c|c|c|c|c|c|}
\hline PBI & $\begin{array}{l}\text { Patients } \\
\text { Mother } \\
\text { Care Control }\end{array}$ & $\begin{array}{l}\text { Father } \\
\text { Care Control }\end{array}$ & $\begin{array}{l}\text { Siblings } \\
\text { Mother } \\
\text { Care Control }\end{array}$ & $\begin{array}{l}\text { Father } \\
\text { Care }\end{array}$ & Control \\
\hline Somatization & & & & $-.49 * *$ & \\
\hline Obsessions-compulsions & & & & $-.49 * *$ & \\
\hline Interpersonal sensitivity & & & $-.39 *$ & $-.53 * *$ & \\
\hline Depression & & & & $-.51 * *$ & $.45^{*}$ \\
\hline Anxiety & & & & $-.48 * *$ & \\
\hline Hostility & & & & $-.44 *$ & \\
\hline Phobic anxiety & & & & $-.53 * *$ & $.49 * *$ \\
\hline Paranoid ideation & $.40 *$ & & $-.42 *$ & $-.51 * *$ & $.42 *$ \\
\hline Psychoticism & & & & $-.66 * *$ & $.46^{*}$ \\
\hline Global severity index & & & & $-.56^{*}$ & $.40 *$ \\
\hline
\end{tabular}

PBI mother $\mathrm{n}=27$, PBI father $\mathrm{n}=26 ; * \mathrm{p}<.05, * * \mathrm{p}<.01$ 


\section{Discussion}

In this study, a group of psychiatric outpatients with different diagnoses were compared with their same-sex healthy siblings. Participants from both groups filled in the questionnaires reliably. The patients scored higher on all SCL-90-R scales, even though the difference was only marginally significant in the case of interpersonal sensitivity and not statistically significant in the case of hostility; psychiatric patients undergoing treatment are indeed not necessarily more aggressive than others. Thus, as expected, the patients were more symptomatic on the broad scale of psychopathology and the difference in outcome was confirmed. Incidentally, even our siblings' ratings were higher on all symptom dimensions (range 0.34 $0.76)$ than were the ratings of the representative general population sample (range $0.22-0.48$ ) studied by Hessel et al. ${ }^{20}$; correspondingly, Global Severity Index was also higher $(0.58 \pm 0.67$ vs $0.38 \pm 0.39)$. In contrast, there were no significant differences between the two groups with regard to the individual PBI ratings. Again, the ratings of all our probands were much more similar to ratings reported for a varied psychiatric in- and outpatient sample than for a representative community sample ${ }^{21}$. Even though it was not significant, the PBI ratings tended towards the expected lower values for parental care and towards higher values for parental control in the patients and one third of the patients indicated no optimal bonding with either parent. Correspondingly, less PBI parental care and more control/overprotection were indicated by schizophrenic than by non-schizophrenic same-sex twins, regardless of whether the subjects were monozygotic or dizygotic ${ }^{22}$ and similar results were found with regard to depression and anxiety ${ }^{23}$. Considering probable differences in perception, our result shows that the parenting style did not differ substantially in the same home.

The most interesting result of the study, presented in Table II, shows 1 . The degree of psychopathology correlated highly and significantly with certain PBI dimensions in the healthy siblings, but not in the patients, and this in spite of the fact that there was a greater ratings range in the patient group. As in only one of the SCL-90 items the average rating was slightly above 2 (range 0 - 4), the lack of association between parenting and psychopathology in the clinical group can not be due to a ceiling effect on the SCL-90-R. 2. The correlations in the non-patients concerned paternal ratings, but not - with two exceptions - maternal ratings. 3. Negative correlations of care with psychopathology seem to be more pronounced than positive correlations with the dimension of control. In summary, the degree of paternal care seems to be most closely related with a lack of mental symptoms in this sample of psychiatric non-patients.

Parental care was estimated to be more important than parental control in general and in depression in particular ${ }^{24}$. Parental attitudes are due, in part, to the offspring's characteristics and these probably have a greater impact on the love and care provided by a parent than on the parental approach to discipline and control ${ }^{25}$; personal characteristics of children may elicit parental warmth ${ }^{26}$ and nonpatients may possibly be better able to elicit such positive parental attitudes. The finding of a greater impact of paternal - compared with maternal - parenting is impressive but difficult to explain; in our previous study we demonstrated a similarly pronounced influence of paternal parenting (also using PBI) on personality disorder pathology in men, but not in women ${ }^{27}$. The present result was obtained in a sample with a majority of over $60 \%$ of women. 
Whereas significant relationships have been found between PBI and SCL-90-R ratings in healthy siblings, practically no such correlations have been found in patients. It follows that in patients presenting a higher degree of psychopathology, parenting - as one of the factors of non-shared (and shared) environment - does not play a substantial role; we speculate that genetic factors are increasingly more important the more pronounced pathology becomes. In the same vein, heritability of major depression has been shown to be greater for more restrictive definitions of the disorder, reflecting its more severe, more pronounced form ${ }^{28}$ and other results suggested unspecific genetic vulnerability for psychotic illness to be dependent on the severity of the overall psychopathology 29 . Incidentally, psychopathology of the patients in our sample was partially of psychotic origin. There is a reciprocal relationship between the importance of environmental stress and genetic factors: With increasing levels of family dysfunction, the proportion of variance in cigarette smoking due to genetic factors decreased, and that due to environmental effects increased ${ }^{30}$.

Thus, our results, achieved with a simple design, are in accord with the results of the studies carried out with much more sophisticated methods. However, we are well aware of the limitations of our study: Only a relatively small sample of same-sex pairs could be recruited and the sample was heterogeneous with regard to psychopathology. This is a correlational study and correlations do not imply causal relationships. Finally, the importance of paternal and not maternal parenting demonstrated in this study is not easy to explain. Therefore, the exploratory character of this investigation should be stressed. In a future study with a larger sample, the results should be verified. Recruiting more subjects and including more sophisticated diagnostic measures would make it possible to conduct separate analyses for psychotic and non-psychotic disorders and to correlate PBI patterns with other dimensions of abnormality, such as externalizing and internalizing psychopathology. Moreover, it would be interesting to include additional measures other than the PBI to assess the characteristics of the home environment.

Sabelli and Carlson-Sabelli ${ }^{31}$ developed a paradigm of "biological priority and psychological supremacy": In every mental process, its biological aspects have priority, while social and psychological aspects have supremacy. Biological processes are essential for psychological function (priority), and are more determined by causal factors and less by choice. Social and psychological processes, being more complex in informational content, have supremacy for control and are more amenable to change by conscious choice. Our results correspond well with this paradigm: The more pronounced the psychopathology the more weight genetically determined biological processes have and the more emphasis is placed on biological therapies. Less pronounced psychopathology may well be due to environmental causes and be more amenable to change by non-biological interventions.

\section{References}

1. Bouchard TJ Jr. Genes, environment, and personality. Science 1994; 264, 1700-1701.

2. Turkheimer E, Waldron M. Nonshared environment: a theoretical, methodological, and quantitative review. Psychol Bull 2000; 126: 78-108.

3. Plomin R, Asbury K, Dunn J. Why are children in the same family so different? Nonshared environment a decade later. Can J Psychiatry 2001; 46: 225-233.

4. Mackinnon A, Henderson AS, Andrews G. The Parental Bonding Instrument: a measure of perceived or actual parental behavior? Acta Psychiatr Scand 1991; 83: 153-159. 
5. Kitamura T, Sugawara M, Shima S, Toda MA. Relationship of order and number of siblings to perceived parental attitudes in childhood. J Soc Psychol 1998; 138: 342-350.

6. Enns MW, Cox BJ, Clara I. Parental bonding and adult psychopathology: results from the US National Comorbidity Survey. Psychol Med 2002; 32, 997-1008.

7. Neale MC, Walters E, Health AC, Kessler RC, Perusse D, Eaves LJ, Kendler KS. Depression and parental bonding: cause, consequence, or genetic covariance? Genet Epidemiol 1994; 11: 503-522.

8. Kerver MJ, van Son MJ, de Groot PA. Predicting symptoms of depression from reports of early parenting: a one-year prospective study in a community sample. Acta Psychiatr Scand 1992; 86: 267-272.

9. Enns MW, Cox BJ, Larsen DK. Perceptions of parental bonding and symptoms severity in adults with depression: mediation by personality dimensions. Can J Psychiatry 2000; 45: 263-268

10. Russ E, Heim A, Westen D. Parental bonding and personality pathology assessed by clinician report. J Personal Disord 2003; 17: 522-526.

11. Nordahl HM, Stiles TC. Perceptions of parental bonding in patients with various personality disorders, lifetime depressive disorders, and healthy controls. J Personal Disord 1997; 11: 391-402.

12. Gerra G, Angioni L, Zaimovic A, Moi G, Bussandri M, Bertacca S, et al. Substance use among high-school students: relationship with temperament, personality traits and parental care perception. Subst Use Misuse 2004; 39 : 345-367.

13. Schweitzer RD, Lawton PA. Drug abusers' perceptions of their parents. Br J Addict 1989; 84: 309-314.

14. World Health Organization. Tenth Revision of the International Classification of Diseases. Chapter V: Mental and Behavioural Disorders. Geneva: WHO; 1991.

15. Parker G, Tupling H, Brown LB. A Parental Bonding Instrument. Br J Med Psychol 1979; 52: 1-10.

16. Parker G. Parental Bonding Instrument: Psychometric properties reviewed. Psychiatr Dev 1989; 4: 317-335.

17. Wilhelm K, Niven H, Parker G, Hadzi-Pavlovic D. The stability of the Parental Bonding Instrument over a 20year period. Psychol Med 2005; 35: 387-393.

18. Derogatis LR. SCL-90-R: Administration, Scoring and Procedures Manual. Minneapolis, National Computer Systems, 1994.

19. Horowitz LM, Rosenberg SE, Baer BA, Ureno G, Villasenor VS. Inventory of interpersonal problems: Psychometric properties and clinical applications. J Consult Clin Psychol 1988; 56: 885-892.
20. Hessel A, Schumacher J, Geyer M, Brähler E. Symptom-Checkliste SCL-90-R: Theoretische Ü berprüfung und Normierung an einer bevölkerungsrepräsentativen Stichprobe. Diagnostica 2001; 47: 27-39.

21. Gilbert P, Gerlsma C. Recall of shame and favouritism in relation to psychopathology. Br J Clin Psychol 1999; 38: 357-373.

22. Onstad S, Skre I, Torgersen S, Kringlen E. Parental representation in twins discordant for schizophrenia. Psychol Med 2003; 23: 335-340.

23. Parker G. Validating an experiential measure of parental style: The use of a twin sample. Acta Psychiatr Scand 1986; 73: 22-27.

24. Mackinnon A, Henderson AS, Andrews G. Parental "affectionless control" as an antecedent to adult depression: A risk factor refined. Psychol Med 1993; 23: 135-141.

25. Kendler KS. Parenting: A genetic-epidemiologic perspective. Am J Psychiatry 1996; 153: 11-20.

26. Lichtenstein P, Ganiban J, Neiderhiser JM, Pedersen NL, Hansson K, Cederblad M, Elthammar O, Reiss D. Remembered parental bonding in adult twins: genetic and environmental influences. Behav Genet 2003; 33: 397-408.

27. Modestin J, Oberson B, Erni T. Possible antecedents of DSM-III-R personality disorders. Acta Psychiatr Scand 1998; 97: 260-266.

28. Kendler KS, Neale MC, Kessler RC, Heath AC, Eaves LJ. The lifetime history of major depression in women. Reliability of diagnosis and heritability. Arch Gen Psychiatry 1992; 50: 863-870.

29. Stassen HH, Bridler R, Hägele S, Hergersberg M, Mehmann B, Schinzel A, Weisbrod M, Scharfetter C. Schizophrenia and smoking: evidence for a common neurobiological basis? Am J Med Genet 2000; 96: 173-177.

30. Kendler KS, Aggen SH, Prescott CA, Jacobson KC, Neale MC. Level of family dysfunction and genetic influences on smoking in women. Psychol Med 2004; 34: 12631269.

31. Sabelli HC, Carlson-Sabelli L. Biological priority and psychological supremacy: a new integrative paradigm derived from process theory. Am J Psychiatry 1989; 146: 1541-1551.

Address for correspondence:

Prof. J. Modestin,

University of Zurich, Department of Psychiatry

Burghölzli Hospital, Lenggstrasse 31,

CH-8032 Zürich, SWITZERLAND

Tel. (+41) 4438421 11; Fax (+41) 443842718

E-mail address: modestin@bli.unizh.ch 